University of Massachusetts Amherst

ScholarWorks@UMass Amherst

Research Briefs

CSCORE: Ronald H. Fredrickson Center for School Counseling Outcome Research \&

Evaluation

2016

\title{
Making the Case for Universal School-Based Mental Health Screening
}

Neil Humphrey

Manchester Institute of Education

Follow this and additional works at: https://scholarworks.umass.edu/cscore_briefs

Humphrey, Neil, "Making the Case for Universal School-Based Mental Health Screening" (2016). Research Briefs. 9.

Retrieved from https://scholarworks.umass.edu/cscore_briefs/9

This Article is brought to you for free and open access by the CSCORE: Ronald H. Fredrickson Center for School Counseling Outcome Research \& Evaluation at ScholarWorks@UMass Amherst. It has been accepted for inclusion in Research Briefs by an authorized administrator of ScholarWorks@UMass Amherst. For more information, please contact scholarworks@library.umass.edu. 


\section{Making the case for universal school-based mental health screening}

Humphrey, N. \& Wigelsworth, M. (2016). Making the case for universal school-based mental health screening. Emotional and Behavioural Difficulties, EarlyView. http://dx.doi.org/10.1080/13632752.2015.1120051

\section{Introduction}

Most children and young people who experience significant mental health difficulties do not access the support that they need (Dvorsky, Girio-Herrera \& Owens, 2014; Kelvin, 2014). This is at least in part due to the predominance of two flawed approaches to identification and referral for intervention (i.e., the 'wait to fail' and 'refer-test-place' models; Dowdy, Ritchey \& Kamphaus, 2010; Glovers \& Alber, 2007) that are both highly variable and result in under-referral (e.g., children who need help are not referred) and late referral (e.g., children are referred only when problems have become deeply entrenched and therefore more resistant to intervention efforts).

One alternative to the above approaches is universal screening as part of schools' mental health provision. Schools are increasingly recognized as a key site for mental health promotion as schooling provides a critical opportunity to effect positive change - it is universal, begins early in life, and entails periods of prolonged engagement with children and young people (totaling around 15,000 hours; Rutter et al., 1979). It has been argued that a critical prerequisite to providing effective school-based prevention and intervention services is the adoption of a population-based approach embodied by a universal screening model. In such a system, all members of the student population in a school undergo brief assessments which may be informed by teachers, parents and/or students themselves, designed to identify those at risk of developing difficulties (Dowdy, Ritchey, \& Kamphaus, 2010; Dvorsky, Girio-Herrera, \& Owens 2014; Glover \&Albers, 2007). The logic is simple: "Before intervention can occur mental health problems must be identified" (Williams 2013, p.24).

There are three potential benefits of such a system. First, by definition, universal screening means that all children and young people are assessed. Theoretically, this should have the effect of reducing the number of those at-risk being overlooked compared to the existing methods noted previously. Second, universal screening provides a baseline for future monitoring and assessment. This means that a more data-driven approach to mental health provision in schools can be adopted. Third, universal screening can offer significant cost savings over time. The basic logic here is that universal screening should lead to earlier intervention for emergent mental health problems, which is less intensive and expensive than targeted interventions for more severe or entrenched problems. However, despite these apparent benefits, universal mental health screening is extremely rare. For example, only $2 \%$ of schools in the US use this approach as part of their routine practice (Romer \& McIntosh, 2005).

In their article, Neil Humphrey and Michael Wigelsworth provide a comprehensive analysis of the challenges and opportunities posed by universal school-based mental health screening.

\section{Methods}


The authors' paper is a discussion piece, and begins by outlining the basic case for universal school-based mental health screening before critically examining a range of key issues. In turn, these are social validity (e.g., the value and social importance attributed to an innovation, expressed in terms of feasibility, acceptability, and utility), the influence of government policy and the relationship between academic attainment and health (e.g., how policy directives may create a barrier to the development of mental health provision in schools), definition and conceptualization (e.g., what do we mean by mental health and related terms?), design and implementation (e.g., training and goal clarification, measure selection and approach to screening, use of different informants, use/sharing of data and the coordination of care), psychometric considerations (e.g., are measures reliable and valid?), accommodation of diversity (e.g., cultural norms and practices), and costs and benefits (e.g., is universal screening cost-effective?).

\section{Results}

Drawing upon the international research base on universal mental health screening in their analysis of the above issues, the authors argue that it is "easier said than done", highlighting a number of challenges that would need to be addressed for such a system to be feasible and to achieve its intended outcomes. These include (but are not limited to):

- In a policy context that often presents the relationship between attainment and health as a zero sum game, a significant 'hook' is needed in order to ensure adequate buy-in to a universal screening system in schools

- Mental health and related terms are not universally agreed or understood

- School staff would need to access training, including goal clarification

- There are a variety of psychometric considerations that complicate the process of measure selection. In particular, predictive validity is key. Measuring sensitivity and specificity are critical considerations in this regard (i.e., do measures accurately predict the onset of mental health difficulties?)

- A universal screening system would need to be 'culturally competent' (i.e., respectful of the various forms of diversity such as gender, cultural, socio-economic, linguistic) to be viable

- Developing and implementing a universal screening system need not be prohibitively expensive (and indeed could lead to cost-savings in the long run), but questions still remain as to how such a system would be funded

\section{Critical Perspective}

Throughout the paper, the authors raise a number of critical perspectives on the prospect of a universal school-based mental health screening system. In particular, they note:

- Concerns expressed by some that children's emotional lives and wellbeing will become the focus of checklists in an education system already driven by 'testocracy' (Watson, Emery, \& Bayliss, 2012)

- Questions about what happens next. That is, effective referral processes and subsequent provision in terms of mental health interventions ("the coordination of care") need to be in place for the 
data produced to serve its intended purpose (i.e., ensuring that children in the early stages of distress are identified early and access the support that they need)

\section{Implications for Practice}

The authors argue that the development of a universal screening system that is administered through schools and addresses the various challenges and issues raised (none of which, they argue, are insurmountable) could be a critical component in the development of a coordinated response to an emerging public health crisis in relation to mental health difficulties among children and young people. Their article concludes with a vision for what an effective system might look like 'at the chalkface' (that is, when implemented in ordinary schools).

Written by Neil Humphrey, Manchester Institute of Education, University of Manchester, UK. Email neil.humphrey@manchester.ac.uk

\section{References}

Dowdy, E., Ritchey, K. \& Kamphaus. R. (2010). School-based screening: A population-based approach to inform and monitor children's mental health needs. School Mental Health, 2, 1-11. doi:10.1007/s12310-010-9036-3.

Dvorsky, M., Girio-Herrera, E. \& Owens, J. S. (2014). School-based screening for mental health in early childhood. In M. Weist (Ed.) Handbook of School Mental Health (pp.297-310). New York: Springer.

Glover, T. A., \& Albers, C. A. (2007). Considerations for evaluating universal screening assessments. Journal of School Psychology, 45, 117-135. doi:10.1016/j.jsp.2006.05.005.

Kelvin, R. (2014). Mental health help "needed in schools.” BBC News Health, March 24. http://www.bbc.co.uk/news/health-26685550.

Romer, D., \& McIntosh, M. (2005). The roles and perspectives of school mental health professionals in promoting adolescent mental health.” In D. L. Evans, E. B. Foa, R. E. Gur, H. Hendin, C. P. O'Brien, M. Seligman, \& B. T. Walsh (Eds.), Treating and Preventing Adolescent Mental Health Disorders, (pp.598-615). Oxford: Oxford University Press.

Watson, D., Emery, C. \& Bayliss, P. (2012). Children's Social and Emotional Wellbeing in Schools: A Critical Perspective. Bristol: Policy Press.

Williams, S. (2013). Bring in universal mental health checks in schools. British Medical Journal 5478, 24-26. doi:10.1136/bmj.f5478. 